\title{
Elitism among albino rats: Genius and overachievement
}

\author{
JAMES H. REYNIERSE \\ Hope College, Holland, Michigan 49423
}

\begin{abstract}
From a larger population of rats that had been trained in a shuttlebox, the records of 40 animals which had shown particularly excellent avoidance performance were identified and examined further. Contrary to the conventional view that shuttlebox avoidance takes many trials to acquire, it was demonstrated that many rats learn the response quickly, showing maintained avoidance throughout a 200-trial session. These results were discussed in terms of particularly important procedures, notably the presence of odors associated with fear, which facilitate rapid acquisition of shuttlebox avoidance.
\end{abstract}

It is a well known fact that shuttlebox avoidance is learned only after considerable practice. Ordinarily, learning the running avoidance response in a shuttlebox requires approximately 100 trials and some rats never learn the response (Bolles, 1970). Although we have occasionally observed excellent performance of individual rats, it was still surprising when a single naive male rat learned the shuttlebox avoidance response after a single brief (.5 sec at $1.3 \mathrm{~mA})$ shock, continuing to avoid efficiently without error for a total of 47 trials until training was discontinued. During this time, avoidance was highly efficient as total CS duration for the 47 trials was $60.2 \mathrm{sec}$, an average of $1.28 \mathrm{sec}$ per trial. Observation of this rat's behavior confirmed his efficient performance as he consistently responded immediately to CS onset with the effective running response.

The remarkable performance of this single rat served as a reminder of previously observed excellent performance in the shuttlebox by other rats. This paper examined the performance of rats from three completed but unrelated studies which used an automated shuttlebox, and reports the performance of an unexpectedly large number of rats which were characterized by unusually high shuttlebox performance.

\section{METHOD}

\section{Subjects}

The records of a total of 234 adult albino Sasco rats from three separate studies were examined further. They included 56 male rats from a study by Reynierse and Rizley (1970), 16 male and 16 female rats from a study by Reynierse and Straw (1973), and 146 male rats from an unpublished study. Rats from these studies were included becau se they all received 200 acquisition trials in a single session. Forty rats $(17 \%)$ of the total population made at least 170 avoidances during acquisition, and it is their scores which are of particular interest.

\section{Apparatus}

The apparatus, two identical $36 \times 4 \times 14$ in. automated shuttleboxes, were constructed of clear Plexiglas and were housed in sound-attenuating enclosures. Shock of $.6 \mathrm{~mA}$ was delivered to the grids by a Grason-Stadler shocker scrambler, Model E1064GS for the 56 rats in the study by Reynierse and Rizley (1970). The remaining Ss received 1.3-mA shock delivered in an identical manner. A Sonalert tone source on the top of each box produced a $2,800-\mathrm{Hz}$ tone at $85 \mathrm{~dB}$, re
.0002 dynes $/ \mathrm{cm}^{2}$. Running responses were monitored by a photocell system consisting of four photocells spaced at equal intervals. Programming and recording were achieved by appropriate relay circuitry.

\section{Procedure}

The procedures were considerably different between experiments; the details of each are described elsewhere (Reynierse \& Rizley, 1970; Reynierse \& Straw, 1973). The rats from the unpublished study employed procedures identical to those used by Reynierse and Straw (1973) with the additional provision that $\mathrm{N}$-length was systematically varied. However, these procedural differences do not appear to be critical for obtaining excellent shuttlebox responding.

In general, the CS-US. interval was always $5 \mathrm{sec}$, both CS and US being response terminated. Upon placement in the apparatus prior to acquisition, the rat remained undisturbed for a $30-\mathrm{min}$ adaptation period. All animals then received 200 acquisition trials in a single session. The intertrial interval varied from approximately $30 \mathrm{sec}$ in some conditions to $80 \mathrm{sec}$ in others, with several intermediate intertrial interval conditions.

\section{RESULTS AND DISCUSSION}

The results, summarized in Tables 1 and 2, clearly demonstrate that a substantial number of rats in our laboratory rapidly learn a shuttlebox avoidance response and make a large number of avoidances over a 200 trial session. Of the 40 rats which met the arbitrary $85 \%$ avoidance criterion, performance ranged from 170-192 avoidances (median $=177)$. Keep in mind that the acquisition criterion included a run of $9 / 10$ avoidances, acquisition was achieved in from 13-62 trials (median = 25).

Laboratory lore and the assertion (Bolles, 1970) that shuttlebox avoidance takes approximately 100 trials is clearly unfounded. The excellent performance in the shuttlebox by a large number of rats does not, however, in any was detract from Bolles's $(1970,1971)$ main point of the role of species specific defense reactions in escape-avoidance learning. Bolles's interpretation can be subsumed nicely under the broad topic of biological constraints on learning (Shettleworth, 1972) or biological boundaries of learning (Seligman \& Haber, 1972), and such a synthesis of psychological and biological factors appear to hold considerable promise for laboratory investigations of animal learning. If anything, excellent performance in the shuttlebox is 
Table 1

Frequency Distribution of Avoidances for 40 Rats in a Shuttlebox Task

\begin{tabular}{lccccc}
\hline & \multicolumn{5}{c}{ Range of Scores } \\
\cline { 2 - 6 } & $170-174$ & $175-179$ & $180-184$ & $185-189$ & $190-194$ \\
\hline $\begin{array}{l}\text { Number } \\
\text { of Rats }\end{array}$ & 10 & 15 & 8 & 5 & 2 \\
\hline
\end{tabular}

support for the species specific defense reaction hypothesis since running was both the escape and avoidance response.

Excellent performance. in some animals suggests that mean performance should also be quite high, and in our laboratory this is indeed the case. Nevertheless, we also find that a few rats are unable to learn the avoidance response within 200 trials, and these rats make relatively few avoidances over an entire session. Thus, while we probably obtain higher levels of shuttlebox avoidance than in most laboratories, measures of variability are probably quite comparable.

Finally, although we have not systematically investigated any of these variables, there are apparently three crucial factors which account for the high levels of avoidance we obtain. First, all rats are initially placed in the apparatus for a lengthy 30-min adaptation period prior to introducing acquisition conditions. Zerbolio, Reynierse, Wiesman, and Denny (1965) demonstrated that a $30-\mathrm{min}$ adaptation period was clearly superior to a 5-min period for a wheel-turn avoidance response, presumably because exploration of the new environment is complete after the longer period and therefore exploration does not interfere with escape-avoidance responding. Secondly, with the exception of the 56 rats from the Reynierse and Rizley (1970) study, our rats are

Table 2

Frequency Distribution of Trials to Acquisition for 40 Rats in a Shuttlebox Task

Range of Scores

11- 21- 31- 41- 51- 61-

$\begin{array}{llllll}20 & 30 & 40 & 50 & 60 & 70\end{array}$

Number

of Rats

$\begin{array}{llllll}10 & 16 & 6 & 6 & 1 & 1\end{array}$

routinely maintained on a reversed light-dark cycle and run during their night. Furthermore, the box is completely darkened, the only illumination coming from the four focused beams of light in the photocell system. Third, and perhaps most importantly, our boxes are "dirty," i.e., a pan located beneath each shuttlebox contains ground corncobs which absorb the urine and fecal material of our rats, thereby retaining and maximizing olfactory stimulation. In an elegant series of experiments, King (1969) demonstrated that the elimination of odors from shocked rats suppressed the latency to run from the shock compartment to the safe box of a one-way avoidance box. It is quite likely that olfactory stimuli present in the feces and urine of shocked rats have an important fear arousal function, thereby facilitating acquisition of avoidance (Reynierse, in press). Such an interpretation is consistent with the evidence for alarm substances as pheromones (Gleason \& Reynierse, 1969) and that mammalian territorial marking in the wild is generated by broad sources of frustration (Ralls, 1971).

\section{REFERENCES}

Bolles, R. C. Species specific defense reactions and avoidance learning. Psychological R eview, 1970, 77, 32-48.

Bolles, R. C. Species specific defense reactions. In F. R. Brush (Ed.), Aversive conditioning and learning. New York: Academic Press, 1971.

Gleason, K. K., \& Reynierse, J. H. The behavioral significance of pheromones in vertebrates. Psychological Bulletin, 1969, 71, 58-73.

King, M. G. Stimulus generalization of conditioned fear in rats over time: Olfactory cues and adrenal activity. Journal of Comparative \& Physiological Psychology, 1969, 69, 590-600.

Ralls, K. Mammalian scent marking. Science, 1971, 171, 443-449.

Reynierse, J. H. Communication elements constraining animal learning and performance. In P. Pliner, T. M. Alloway, and L. Krames (Eds.), Comparative aspects of nonverbal communication. N ew York: Plenum Press (in press).

Reynierse, J. H., \& Rizley, R. C. Stimulus and response contingencies in extinction of avoidance by rats. Journal of Comparative \& Physiological Psychology, 1970, 73, 86-92.

Reynierse, J. H., \& Straw, R. G. Generalization of a Capaldi sequential analysis to the aversive case. Bulletin of the Psychonomic Society, 1973, 1, 363-364.

Seligman, M. E. P., \& Haber, J. Biological boundaries of learning. New York: Appleton-Century-Crofts, 1972.

Shettleworth, S. J. Constraints on learning. In D. S. Lehrman, R A. Hinde, and E. Shaw (Eds.), Advances in the study of behavior. Vol. 4. New York: Academic Press, 1972.

Zerbolio, D. J., R eynierse, J. H., Weisman, R. G., \& Denny, M. R. Pseudoconditioning? Journal of Comparative \& Physiological Psychology, 1965, 59, 271-274.

(Received for publication April 5, 1974.) 